\title{
On the Relationship of Indicators of Sustainable Development, Quality of Life and the Share of Creative Middle Class
}

\author{
Irina Roshchina ${ }^{1, *}$, Evgeniya Nekhoda $^{1}$, and Galina Kalyanova ${ }^{1}$ \\ ${ }^{1}$ Tomsk State University, Institute of Economics and management, 634050 Lenin Avenue, 36, Tomsk, \\ Russia
}

\begin{abstract}
This article describes the study of existence of the relationship between individual factors of sustainable development from a qualitative point of view. It is revealed that new essential characteristics of the "middle class", connected with sustainable development, are being formed. This makes it necessary to display them by introducing a new concept of "creative middle class". The purpose of this study is to identify the relationship between improving the environment, the quality of life of the population, the processes of formation of a creative middle class and the results of socio-economic policies to ensure sustainable development of the territory. This study was conducted on the basis of a semi-formalized mass interview. Sustainability is considered for two regions of Siberia (Kemerovo and Tomsk regions), which differ in the specialization of economies: the mining region and the innovation region. In the RIA rating of the Russian regions on the quality of life, these regions, despite the different specialization of economies, occupy fairly close positions, being in the middle of the rating table. The hypothesis regarding the role of the creative middle class as the main subject and the main driver of socioeconomic transformations for ensuring the sustainable development of the region in the long term and improving the quality of life of the population has been partially confirmed. This can be explained by the fact that the process of forming a creative middle class is at the initial stage. Manifestations of innovative features in the economic and social activity of the subjective middle class in the Tomsk region were not identified.
\end{abstract}

\section{Introduction}

Studies of single-industry mining territories functioning allow us to conclude that material well-being, despite its importance, is not a key factor determining a person's satisfaction with life [1-2]. Exceptionally material values are gradually being replaced by socioeconomic values, such as: a healthy lifestyle, preservation of the environment, personal development, spiritual improvement [3-6].

\footnotetext{
*Corresponding author: $\underline{\text { riv58@yandex.ru }}$
} 
For example, the rating of the conditional index of happiness, carried out by the NewsEffector Monitoring Agency in conjunction with the Regions of Russia Regional Research Fund, for the 100 largest Russian cities, among which 11 were single-industry municipalities, revealed the following trend: 9 from of 11 single-industry towns were in the second half of the rating. The monotowns of the Kemerovo region, such as Novokuznetsk, Prokopyevsk, practically close this rating. The main reasons for the discontent of the respondents were, firstly, the environmental problems of the city, secondly, the dynamics of urbanistic development and the safety of living, and, thirdly, the level of income. Almost half of the single-industry municipalities participating in the survey have the most difficult environmental and socio-economic situation and risks of its worsening [7].

At the same time, it should be noted that shifting the emphasis in the study of complex socio-economic systems only to qualitative factors also does not allow getting the correct idea of the results and prospects of socio-economic development of the region. For example, an analysis of the world index of happiness indicates the absence of its direct dependence on income and general well-being, since it is mainly oriented towards the senses of development and justice. However, focusing attention only on subjective assessments also does not allow getting an adequate idea of the processes of sustainable functioning of countries and regions.

The strategic direction for the development of most modern economies in the short term (until 2030) and in the long term (until 2050) is sustainable development (SD) in accordance with the Agenda for Sustainable Development [8]. In the refined concept "Agenda for Sustainable Development for the Period until 2030" 17 global goals are formulated, to achieve which it is expected to solve 169 tasks, assessed by 230 indicators" [9].

Sustainable development and quality of life are interconnected and interdependent. As an acknowledgment of the relationship between the processes of sustainable development and improving the quality of life of the population, one can cite an example from the Strategy for Sustainable Development for Great Britain (1998): "Sustainable development ... This is to ensure a better quality of life for all, now and for the generations to come."

One of the main problems in assessing sustainable development is the identification of its representative indicators, as well as the characteristics of processes that are interrelated and interdependent with it and covering the economic, social and environmental spheres [10].

The purpose of this study is to identify the relationship between improving the quality of life of the population, the processes of formation of the creative middle class and the results of socio-economic policies to ensure sustainable development of the territory.

The hypothesis of the study is the substantiation of the position that the creative middle class is the main subject and the main driver of socio-economic transformations to ensure sustainable development of the region in the long term and improve the quality of life of the population.

The concept of "middle class" appeared as a reaction to the processes of functioning and development of a consumer society, which provides for the presence of two pronounced poles (in terms of wealth / income; in terms of ownership; etc.). As a result, as the consumer society functions and develops, a special social layer has been steadily formed, which acts as a kind of buffer between these poles. In the conditions of Industry 4.0, it is necessary to take into account that transformation processes affect all spheres of socioeconomic development. The ideas of the middle class do not remain unchanged. If earlier (for a consumer society) it was enough to use indicators of material content to characterize the middle class, in modern conditions the middle class is called upon to fulfill the role of a driver of socio-economic development. In this regard, in our opinion, to identify the 
features of the current stage of socio-economic development, it is more correct to use the term "creative middle class" rather than "middle class".

The creativity of the middle class (in the broad sense) in the framework of this study, we consider as the ability to change and its active implementation both in relation to their own position in society and in relation to socio-economic processes in general. By the subjective middle class, we mean the part of the population that identifies itself with the middle class.

This study was conducted on the basis of a semi-formalized mass interview. The choice of this method for data collection as the main method is due to the fact that 1) it allows combining quantitative and qualitative approaches; 2) it provides a more correct account of self-identification by reducing the degree of formalization. The necessity and feasibility of taking into account not only objective but also subjective assessments is due to the fact that in the framework of this study the quality of life is considered (in accordance with the WHO interpretation of 1948) as a subjective perception by a person of their own position, taking into account goals, cultural and value orientations, accepted in society.

The study was carried out in two stages. At the first stage, a mass survey was conducted using quantitative and qualitative methods to identify self-identifying oneself with the middle class (subjective middle class). At the second stage, signs were revealed by which respondents related themselves to the creative middle class, and then among this group they were selected with clearly defined certain value orientations (for self-realization, creativity, economic and social activity) for the subsequent in-depth interview.

\section{Materials and Methods}

During several decades, many different approaches have been developed to assess the effectiveness of sustainable development processes and mechanisms for its support. So, for example, Russian researches Bobylev S., Zubarevich N., Solovyova S. developed an index of sustainable development for Russia as an integral indicator of sustainable development, which adapts the basic principles of the methods for calculating the adjusted net accumulation indices of the World Bank and UNDP human development.

In 2002-2013 in the Kemerovo, Samara and Tomsk regions, in the city of Moscow, studies were conducted on the development of indicators of sustainable development. So, for example, in the Tomsk Region, an "Integrated System of Indicators of Sustainable Development of the Tomsk Region" was developed, providing for 38 indicators, subdivided into three groups of indicators: key, additional and specific.

If we consider sustainability not narrowly (as economic stability from the point of view of preserving or increasing the total capital of society over time), but broadly (as the coordination of the development of the "triple union" of the economy, society, nature), then in Russia there are "unstable" trends (in development human, physical, natural and institutional capital) [11-14].

An assessment of sustainability change for 154 countries for 2006-2016 on three components of economic sustainability was carried out by the non-governmental research organization Sustainable Society Foundation (Netherlands). Whereas in 2006 Russia ranked 59th in terms of sustainability of human capital, 140th in terms of sustainability of natural capital, and 49th in terms of sustainability of production capital, in 2016 Russia was ahead of 12 in terms of sustainability of production capital countries, but on the other two characteristics negative changes are observed: in terms of the development of human capital, Russia is ahead of 5 countries, and in terms of the sustainability of natural resource potential -4 countries. Given seemingly positive changes in the development of domestic human capital (growth rate of approximately 11\% for 1990-2017), a more detailed analysis should lead to the opposite conclusion: Russia will have to try to maintain its place among 
the first 30 countries of the world. Indeed, the corresponding indicator for the countries of Eastern Europe and Central Asia is $18.1 \%$, for the countries of East Asia and Oceania $41.8 \%$.

The main process that reduces the stability of the economy is Russia's continued global specialization in the supply of primary hydrocarbon energy, wood, minerals, low-tech goods, ferrous and non-ferrous metals, and agricultural products. Russia ranks sixth in coal mining. In Russian exports, the share of machinery and equipment does not exceed $7 \%$, while their share in imports is more than $50 \%$.

Further preservation of international economic specialization will strengthen the dependence of the Russian economy on the situation in world commodity and financial markets, on the state of political relations with the USA, the EU, and China. All this will significantly complicate Russia's access to the trajectory of sustainable development.

Consider sustainability in two regions of Siberia (Kemerovo and Tomsk regions), which differ in the specialization of economies.

The Kemerovo region is a "mono-region", the dominant city-forming sphere of which is the coal and mining industries (64.7\%). There is a lot of dependence on exports, while the domestic coal market, with its huge potential, is not developing. Over the past 10-15 years, the only source of development for the industry was export: domestic coal consumption declined annually by $1 \%$, while exports grew by $11 \%$. In the Kemerovo region, 17 municipalities are included in the list of single-industry municipalities:

1) Coal mining: Leninsk-Kuznetsk, Tashtagol, Prokopyevsk, Anzhero-Sudzhensk, Belovo, Berezovsky, Kiselevsk, Krasnobrodsky, Mezhdurechensk, Osinniki, Polysaevo.

2) Metallurgical industry: Novokuznetsk, Guryevsk

3) Production and distribution of electricity, gas and water: Kaltan.

4) Engineering: Yurga.

5) Railway: Taiga.

6) Production of building materials: Topki.

In these conditions, ensuring sustainable development is of particular relevance.

According to the results of the assessment of investment attractiveness of 2017, Tomsk region is included in the category of "average investment attractiveness" (first level), which was confirmed in 2018, however, its rating was lowered in comparison with 2016 to IC4.

In the Tomsk region, food production occupies a leading position in the structure of the manufacturing industry. So, for example, in 2017 , food production amounted to $16.4 \%$ of the total manufacturing output. However, it should be noted that this industry is characterized by a model of economic growth, mainly focused on an accelerated increase in prices with a slight increase in production in the context of insufficient use of available reserves for development. If the food industry of the Tomsk region in 2018 was characterized by a gradual deceleration and stabilization of growth rates, then textile and clothing production is characterized by a sharp drop from $12 \%$ growth rate (in the context of a moderate growth in producer prices restrained by import of products) to negative levels more than $3 \%$.

If in the manufacturing industries of the Tomsk Region as a whole there is a slight decrease in annual production indices, then in engineering there is a sharp drop in the production of computers, electronic and optical products, and for the production of machinery and equipment. For the economy of the Tomsk region, serious problems in the processing of wood and the production of wood products cannot be overlooked, associated primarily with the use of production capacity at an average of only $50 \%$.

The human development index of the Tomsk region equal to 0.891 (11th place among the regions of the Russian Federation), corresponds to the level of human development in Spain, which occupies 26th place in the world. For the Kemerovo region, the human development index is 0.848 (53rd among the regions of the Russian Federation). 
A positive factor for expanding the prospects for the development of the regional economy is the growth of personnel engaged in research and development. In the Tomsk Region in 2017, compared to 2013, the number of researchers increased by almost $6 \%$, technicians by almost $50 \%$, and support staff by approximately $11 \%$. The number of innovative enterprises has also increased. There are conditions for self-realization of youth through a knowledge-based business. The number of young scientists and specialists implementing innovative projects has increased. Nevertheless, the human potential in the Tomsk region is not used rationally enough, which can be illustrated by some characteristics of the labor market. The registered unemployment rate in 2018 in the Tomsk Region amounted to $1.3 \%$ of the total number of economically active population, and $0.9 \%$ in Russia. Of the applicants to the state employment service in 2018 for assistance in finding employment, nearly $70 \%$ (68.6\% more precisely) were employed. One in four of the unemployed was between 25 and 29 years old, more than $20 \%$ of the unemployed have higher education. This allows us to assess the prospects for building human potential for this age group in the Tomsk region as not very favorable.

The main problems for single-industry municipalities of the Kemerovo region are: a further decline in the population; population aging (increase in middle age); migration outflow of the population. To increase economic activity and reduce unemployment, it is necessary to take into account the specific features of single-industry municipalities:

- low professional mobility of workers released from city-forming enterprises in other areas of the economy due to their narrow production specialization;

- low geographical mobility of the labor force, caused by the unwillingness or refusal of the unemployed to go to work in a neighboring village, even if it takes a little time.

The index of the quality of life of the world's population most accurately characterizes the degree of economic stability achieved.

It should be noted that in the RIA rating of the Russian regions on the quality of life (according to Rosstat, the Ministry of Health, the Ministry of Finance, the Central Bank and other open sources), these regions, despite the different specialization of economies, occupy fairly close positions, being in the middle of the rating table. Of the 85 possible places, Tomsk Oblast is in 51th place (a combined rating score of 44.469), and Kemerovo Oblast is in 54th place (a combined rating score of 43.260). However, if compared to 2017, the Kemerovo Region improved its rating position, rising from 56th place, then Tomsk Region fell two places (from 49th). This rating is based on the analysis of 70 indicators for 11 groups of basic characteristics included in the quality of life by most researchers and a variety of methods:

1) The level of income of the population.

2) Employment and labor market.

3) Housing conditions of the population.

4) Security of residence.

5) The demographic situation.

6) Public health and educational level.

7) Provision with objects of social infrastructure.

8) The level of economic development.

9) The level of development of small business.

10) Development of the territory.

11) Development of transport infrastructure.

In the Tomsk region, the share of the population with incomes below the subsistence minimum is steadily growing, gradually approaching almost a $20 \%$ mark. There is a steady decline in the share of the population with high incomes or with slightly differing upwards from the average values. Thus, we can conclude that the application of standard approaches and mechanisms to enhance economic growth in the Tomsk region cannot provide a 
transition to a qualitatively different development model. And without this, a technological breakthrough in the Tomsk region in the foreseeable future is impossible.

Positive changes in the structure of cash incomes of the population are associated with an increase in the share of income from entrepreneurial activity and property income, although the level of 2014 has not been reached. Wages are now also not the only source of income, accounting for less than $47 \%$. This can be considered as a result of a change in the behavioral model of the population of the Tomsk region, including in the labor market.

The service sector in the Tomsk region is quite developed, accounting for more than $40 \%$. Since 2017 , the negative trend of reducing the opportunities for the population to receive services in the field of healthcare and sanatorium and resort treatment and recreation has gradually begun to weaken.

In the Tomsk region, for the first time, a concept for the implementation of a publicprivate partnership project "Kindergartens of the Tomsk Region. However, the coverage of children with preschool education is less than $70 \%$. Almost a third of students in the educational programs of primary, basic and secondary general education study in the second shift. The number of organizations providing training in educational programs for primary, basic and secondary education in 2017 did not reach the level of 2013. There was a tendency to reduce the output of bachelors, specialists, and masters by educational organizations of the Tomsk Region.

Тем не менее, имеются и позитивные результаты: 1) в учреждениях дополнительного образования в сфере культуры наблюдается рост числа обучающихся среди взрослого населения города Томска и учащихся групп развития, изостудий, подготовительных классов; 2) почти двукратное увеличение количества участников культурно-досуговых мероприятий.

Nevertheless, there are positive results: 1) in institutions of additional education in the field of culture, there is an increase in the number of students among the adult population of the city of Tomsk and students in development groups, art studios, and preparatory classes; 2) an almost twofold increase in the number of participants in cultural and leisure activities.

The introduction of new forms of educational work of the museum has provided an increase in the number of visitors to the Museum of History of Tomsk. The number of exhibition projects of the museum, as well as visits to virtual exhibitions on the site of the institution has increased. A special cycle of classes for students has been developed, included in the curriculum.

In the Kemerovo region in the period from the beginning to the middle of the 2000th there was a reduction in catering facilities, hospital facilities, gas stations, social services institutions, cultural and leisure facilities, which negatively affected the quality of life of the population in a single-industry municipality.

The identified features and problems of ensuring sustainable development of the analyzed regional economies and briefly presented in this article should be detailed in order to get an idea of the group of the population that is able to actively participate in resolving sustainable development problems. The study of the correctness of the prolongation of ideas about such a driving force, which was formed under the conditions of a consumer society such as the middle class, for an economy that is transitioning to new conditions (Industry 4.0), was carried out using the example of the Tomsk Region.

\section{Results and Discussion}

The following results were obtained.

Among the population of the Russian Federation as a whole to the middle class in 20032015 about 52\% identified themselves. In 2018 (as part of this study), in Tomsk Oblast, out of 697 people surveyed (over the age of 18 ), on the basis of self-identification, $80.8 \%$ are 
assigned to the middle class. However, in terms of the total number of respondents, the creative middle class was about 53-56\%.

Based on the interpretation of creativity adopted in this study, we first of all studied the following behavioral characteristics: priority of personal or public interests; the ability to independently achieve your goals; the presence of an active life position; economic and social activity.

The majority of respondents $(59.1 \%)$ recognize the priority of personal interests over public ones, and a little more than $25 \%$ agree with the need to limit personal interests in the name of public ones.

At the same time, about $70 \%$ are able to independently achieve their goals and $30 \%$ need help (relatives, friends, employer, government, etc.).

According to the importance of activity in different spheres of life, respondents were practically divided into two equal parts. The advantage in favor of those recognizing this characteristic as significant was only slightly more than $7 \%$.

In the analysis of economic activity in the framework of this study, it was important to identify areas of employment and to determine how much they coincide with the priority areas for the development of the regional economy. A contradiction was revealed. On the one hand, $61.5 \%$ do not know the strategic goals of the socio-economic development of the Tomsk Region, $38 \%$ do not associate their economic activity with the implementation of the official tasks of regional development, and on the other hand, almost half of the respondents are engaged in strategically priority areas of activity (development and production of high technology products, entrepreneurship, agriculture).

In terms of the importance of social activity, the difference turned out to be even smaller - only $5.55 \%$. As for the forms of social activity, we analyzed activities in the immediate environment of citizens (family, work, neighbors, acquaintances) and activities in a wider public sphere (large-scale social projects and social assistance to strangers, political activity). At the same time, activities in a wider public sphere prevail in importance and amount to almost $35 \%$ compared with activities in the immediate environment of citizens (a little over $7 \%$ )

\section{Conclusion}

As a result of the study, it was confirmed that the higher the level of quality of life is, the more opportunities for self-realization of a person in various forms exist. Accordingly, conditions are being formed for intensifying the processes of the formation of a creative middle class. And, on the contrary, in the presence of problems of ensuring the sustainable development of the territory, the formation of a creative middle class slows down, in turn, activating the formation of "anti-sustainable" trends.

The economic crisis necessitated a change in the approach to measuring sustainable development indicators. If the planning of socio-economic development of the region for the long term does not take into account the deformation of human capital, the depletion of natural resources, then we can miss the process of forming "anti-sustainable" trends.

In an unfavorable demographic situation, it is important to create conditions for the effective use of human potential reserves.

According to the results of a study of the qualitative aspects of development sustainability using the example of regions with different specialization of economies, we can assume the need to take into account the size and influence of institutional capital along with the traditionally recognized "triple union" of spheres (economic, social and environmental). This hypothesis will be tested by us in the next study. 


\section{Acknowledgement}

The research is done under the financial support of the Russian Foundation for Basic Research, Research Project № 18-410-700004 p_a "Creative middle class as a driver of sustainable development of the region and improving the quality of life (on example of Tomsk region)".

\section{References}

1. I. Roshina, N. Artyukhova, RRI 2016 Future Academy, 823-829 (2017)

2. N. Artukhova, I. Roshchina, G. Kalyanova, M. Katz, E3S Web Conf., 41, 04008 (2018)

3. Global Wealth Report 2018 (CSB, Washington, 2018)

4. The changing nature of work. World development report 2019 (The World Bank, Washington, 2018)

5. The Changing Wealth of Nations 2018. Building a sustainable Future (WBG, Washington, 2017)

6. The Legatum Prosperity Index. 12edition. Country Profiles- 2018 (LI, London, 2018)

7. I. Roshina, N. Artyukhova, WELLSO 2016 Future Academy, 43-50 (2017)

8. The Sustainable Development Goals Report (United Nations, New York, 2017)

9. Transforming our World the 2030. Agenda for sustainable Development (United Nations, New York, 2015)

10. World Development indicators 2018 (WBY, Washington, 2018)

11. Human Development Indicators and Indicies: 2018. Statistical Update Team (UNDP, Genova, 2018)

12. Our Common Future. Report of the World Comission on Environment and Development (United Nations, New York, 2018)

13. Statistical Yearbook 2018 (United Nations, New York, 2018)

14. The Global Competitiveness Report 2018 (WEF, Genova, 2018) 